\title{
Healthcare Information Systems - Requirements and Vision
}

\author{
John G. Williams \\ Professor of Health Services Research, Swansea University, UK \\ Director of Health Informatics Unit, Royal College of Physicians, UK Swansea University
}

\begin{abstract}
The introduction of sophisticated information, communications and technology into health care is not a simple task, as demonstrated by the difficulties encountered by the Department of Health's multi-billion programme for the NHS. This programme has successfully implemented much of the infrastructure needed to support the activities of the NHS, but has made less progress with electronic patient records. The case for health records that are focused on the individual patient will be outlined, and the need for these to be underpinned by professionally agreed standards for structure and content. Some of the challenges will be discussed, and the benefits to health care and clinical research will be explored.
\end{abstract}

